BMJ Open

Diabetes

Research

\& Care

\title{
Preserved glucagon-like peptide-1 responses to oral glucose, but reduced incretin effect, insulin secretion and sensitivity in young Asians with type 2 diabetes mellitus
}

To cite: Yeow TP, Pacini G, Tura A, et al. Preserved glucagon-like peptide-1 responses to oral glucose, but reduced incretin effect, insulin secretion and sensitivity in young Asians with type 2 diabetes mellitus. BMJ Open Diabetes Research and Care 2017;5: e000352. doi:10.1136/ bmjdrc-2016-000352

This study has been presented at (1) General Poster Session and Moderated Poster Discussion at the American Diabetes Association's 76th Scientific Sessions, June 10-14, 2016. in New Orleans, Louisiana, and (2) Young Investigator Award at the Diabetes Asia Conference, October 6-9, 2016 in Kuala Lumpur, Malaysia.

Received 30 October 2016 Revised 31 December 2016 Accepted 24 January 2017

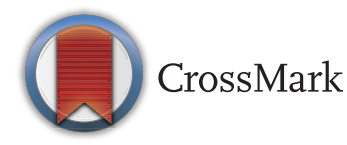

For numbered affiliations see end of article.

Correspondence to Dr Toh Peng Yeow; tohpeng. yeow@pmc.edu.my

\author{
Toh Peng Yeow, ${ }^{1,2}$ Giovanni Pacini, ${ }^{3}$ Andrea Tura, ${ }^{3}$ Chee Peng Hor, ${ }^{4,5}$ \\ Shueh Lin Lim, ${ }^{2}$ Florence Hui Sieng Tan, ${ }^{6}$ Chin Voon Tong, ${ }^{2}$ \\ Janet Yeow Hua Hong, ${ }^{7}$ Fuziah Md Zain, ${ }^{7}$ Jens Juul Holst, ${ }^{8}$ \\ Wan Nazaimoon Wan Mohamud ${ }^{9}$
}

\section{ABSTRACT}

Objective: Youth onset type 2 diabetes mellitus (YT2DM) is a globally rising phenomenon with substantial Asians representation. The understanding of its pathophysiology is derived largely from studies in the obese African-American and Caucasian populations, while studies on incretin effect are scarce. We examined the insulin resistance, $\beta$-cell function (BC), glucagon-like peptide (GLP)-1 hormone and incretin effect in Asian YT2DM.

Research design and methods: This case-control study recruited 25 Asian YT2DM and 15 healthy controls, matched for gender, ethnicity and body mass index. Serum glucose, insulin, C peptide and GLP-1 were sampled during 2-hour oral glucose tolerance tests (OGTTs) and 1-hour intravenous glucose tolerance tests (IVGTTS). Insulin sensitivity was derived from the Quantitative Insulin Sensitivity Check Index (QUICKI), Oral Glucose Insulin Sensitivity Index (OGIS) in OGTT and surrogate index of $\mathrm{SI}$ from the minimal model (calculated SI, CSI). Acute insulin response (AIR) was obtained from IVGTT. Total BC was computed as incremental area under the curve of insulin/incremental area under the curve of glucose, during OGTT $\left(\mathrm{BC}_{0 \mathrm{G}}\right)$ and IVGTT $\left(\mathrm{BC}_{\mathrm{IV}}\right)$, respectively. Disposition index (DI) was calculated using the product of insulin sensitivity and insulin secretion. GLP-1 response to oral glucose was calculated as incremental area under the curve of GLP-1 $\left(\triangle A \cup C_{G L P-1}\right)$. Per cent incretin effect was estimated as $100 \times\left(\mathrm{BC}_{\mathrm{OG}}-\mathrm{BC}_{\mathrm{IV}}\right)$ / $\left.\mathrm{BC}_{\mathrm{OG}}\right)$.

Results: The YT2DM had marked impairment in BC ( $>80 \%$ reduction in $\mathrm{AIR}$ and $\mathrm{BC}_{\mathrm{OG}}, \mathrm{p}<0.001$ ) and lower QUICKI $(p<0.001)$, OGIS $(p<0.001)$ and CSI $(p=0.015)$ compared with controls. There was no difference in GLP-1 at all time points and $\triangle A U C_{G L P-1}$ but the per cent incretin effect was reduced in the YT2DM compared with controls $(12.1 \pm 8.93$ vs $70.0 \pm 4.03$, $p<0.001$ ).

Conclusions: Asian YT2DM showed similar GLP-1 response to oral glucose as controls but reduced incretin effect, $B C$ and insulin sensitivity. The lack of

\section{Significance of this study}

What is already known about this subject?

- Youth onset type 2 diabetes mellitus (YT2DM) is characterised by obesity, insulin resistance and $\beta$-cell impairment.

What are the new findings?

- In this study, the Asian YT2DM have preserved glucagon-like peptide (GLP)-1 response to oral glucose but decreased incretin effect, $\beta$-cell function and insulin sensitivity.

How might these results change the focus of research or clinical practice?

- Further clinical studies in YT2DM are needed to establish the possibility of 'GLP-1 resistance' and if incretin-based therapy can benefit glycemic control in YT2DM.

compensatory mechanisms, as shown by the DI may be partly ascribed to the impaired incretin effect, similar to that of adult T2DM.

Trial registration number: NMRR-12-1042-13254.

\section{INTRODUCTION}

Type 2 diabetes mellitus (T2DM) among the youth is a rising phenomenon which poses a public health challenge because development and progression of clinical complications may be more rapid, and associated with greater mortality when the onset of T2DM is early. ${ }^{12}$ In the USA, up to $45 \%$ of diabetes in adolescents cases are now being attributed to T2DM. ${ }^{3}$ Adolescents of Asian descent are major contributors of pediatric T2DM. ${ }^{45}$

Studies suggest that impaired glucose tolerance and T2DM in obese youth is due to a 
combination of progressive and rapid deterioration of $\beta$-cell function (BC) in the presence of insulin resistance. ${ }^{6}{ }^{7}$ However, the degree of insulin resistance and the ability of the $\beta$-cell to secrete sufficient insulin to adequately respond to the peripheral insulin resistance state appear to vary among different populations and appear to be influenced by genetic and environmental factors. ${ }^{18}$ Most studies on youth onset T2DM (YT2DM) were conducted on African-American and Caucasian obese subjects. ${ }^{9-11}$ Pathophysiological characterization studies among the Asians and studies on incretin effect among youth with T2DM are limited.

The aim of our study was the characterization of a multiethnic Asian population of youth with T2DM and control subjects with comparable gender, ethnicity and body mass index (BMI). We accomplished this characterization by (1) examining insulin resistance and BC both from oral and intravenous glucose tolerance tests (IVGTT); (2) assessing the incretin hormone (glucagonlike peptide-1, GLP-1) response during the oral test; and (3) estimating the 'incretin effect' by relating the differences in $\beta$-cell responses, from insulin and $\mathrm{C}$ peptide, between stimulation with oral and intravenous glucose.

\section{RESEARCH DESIGN AND METHODS}

Subjects with diabetes were recruited from the specialist clinics of three referral hospitals in Malaysia (Penang, Putrajaya and Sarawak General Hospitals). They had been diagnosed and managed as T2DM based on the WHO criteria ${ }^{12}$ with either clinical features of insulin resistance or long clinical course of non-insulin dependency (ie, absence of diabetic ketoacidosis despite defaulting from insulin therapy). Controls without diabetes and without blood relation, matched for gender, ethnicity and BMI were recruited from community via word of mouth. All participants were $<25$ years old at the time of assessment.

The participants attended the clinical research centers on three different occasions within a 40-day period to undergo baseline assessment, CT scan for abdominal subcutaneous and visceral fat quantification, oral glucose tolerance test (OGTT) and IVGTT. All subjects underwent similar evaluation.

The study was registered at the Malaysian National Medical Research Register (NMRR 12-1042-13254) on November 29, 2012. The Malaysian Medical Research and Ethics Committee approved the study on June 28, 2013. Written informed consents were obtained from all participants. For participants younger than 18 years old, assent were obtained using a separate age appropriate assent form, alongside written consent from the minor's parents(s) or guardian(s).

\section{Baseline history, anthropometric measurement and laboratory assessment}

Baseline information included age, ethnicity, birth history and family history of diabetes, age of diagnosis, duration of diabetes and use of oral antidiabetic agents (OADs) were obtained during baseline assessment. Weight, height, BMI, waist and hip circumferences, blood pressure, presence of acanthosis nigricans and Tanner staging were documented from physical examination. Microalbuminuria was defined as microalbumincreatinine ratio of $>2.5 \mathrm{mg} / \mathrm{mmol}$ for men and $>3.5 \mathrm{mg} /$ mmol for women on at least two separate occasions.

Fasting venous blood samples (after an overnight fast of 10 hours) were drawn for plasma glucose, lipid profile, glycated hemoglobin (HbA1c), renal profile, liver function tests, glutamic acid decarboxylase-65 antibody (GAD65 $\mathrm{Ab}$ ) and Islet antigen-2 antibody (IA2 $\mathrm{Ab})$.

\section{Abdominal fat quantification}

Limited axial CT scan of the abdomen was performed at L4-L5 intervertebral level. The area of abdominal adipose tissue was calculated using OsiriX imaging software. Tissue with Hounsfield unit between -30 and -190 was considered as adipose tissue. Abdominal adiposity was quantified as total, subcutaneous and visceral adipose tissues.

\section{OGTT and IVGTT}

Each subject underwent OGTT and IVGTT on two separate occasions, 24-48 hours apart. For female subjects, these tests were performed during the follicular phase of menstrual cycle. On both occasions, the subjects were studied in a recumbent position after overnight (10 hours) fasting, restraining from medication and tobacco use. For the subjects with diabetes on OADs, the medications were stopped for a minimum of 5 days before any test. Short or intermediate acting insulin was started in the interim to maintain glycemic control, at the discretion of the attending endocrinologists. Subjects regularly treated with long-acting insulin were temporarily changed to short or intermediate acting insulin the night before the tests. The last dose of insulin was given at least 12 hours before the tests to avoid interference with the measurements. Subjects on OADs restarted their usual medications after completion of OGTT and IVGTT.

OGTT-Glucose, insulin and C peptide were sampled at time $0,30,60,90,120 \mathrm{~min}$ after a glucose load $(1.75 \mathrm{~g} / \mathrm{kg}$, maximum $75 \mathrm{~g})$. GLP-1 hormone was sampled at time $0,15,30,60$ and $90 \mathrm{~min}$ after the glucose load.

IVGTT-A cannula was inserted in an antecubital vein for blood sampling. Basal blood for measurement of glucose, insulin and $\mathrm{C}$ peptide were collected at time -10 and $-1 \mathrm{~min}$, after which glucose $(300 \mathrm{mg} / \mathrm{kg}$ body weight) was infused into a contralateral vein within $30 \mathrm{~s}$, starting at time 0 . Blood was then sampled for glucose, insulin and $\mathrm{C}$ peptide at time $3,5,6,8,10,15,20,25$, $30,40,50$ and 60 min postbolus glucose. ${ }^{13}$ 


\section{Biochemical measurement}

Serum insulin and $\mathrm{C}$ peptide were measured on TOSOH ALA System Analyzer using two-site immunoenzymometric assay kits (ST AIA-PACK IRI and ST AIA-PACK C peptide II, respectively) supplied by TOSOH Corporation, Shiba-koen First Bldg., 3-8-2 Shiba, Minato-ku, Tokyo 105-8623 Japan. Interassay coefficient of variation (CV) for insulin at 62 and $146 \mu \mathrm{U} /$ $\mathrm{mL}$ were $8.8 \%$ and $4.9 \%$, respectively, and for $\mathrm{C}$ peptide at 2.0 and $18.1 \mathrm{ng} / \mathrm{mL}$ were $8.3 \%$ and $7.9 \%$, respectively. The insulin and $\mathrm{C}$ peptide measurements were changed to SI units for subsequent computation and reporting.

Both GAD65 Ab and IA2 Ab were measured using solid phase enzyme immunoassay (IBL International GMBH). The intra-assay $(\mathrm{n}=5) \mathrm{CVs}$ for GAD65 Ab calculated at 16.9 and $64.94 \mathrm{IU} / \mathrm{mL}$ were $7.6 \%$ and $8.3 \%$, respectively, while the corresponding interassay $(n=5)$ CVs were $8.4 \%$ and $13.8 \%$, respectively. The intra-assay $(\mathrm{n}=5)$ CVs for IA2 Ab calculated at 8.68 and $54.02 \mathrm{IU} /$ $\mathrm{mL}$ were $15.7 \%$ and $9.8 \%$, respectively, while the corresponding interassay $(n=5)$ CVs were $18.6 \%$ and $13.7 \%$, respectively. GAD65 $\mathrm{Ab}$ and/or IA2 $\mathrm{Ab}$ of $>30 \mathrm{IU} / \mathrm{mL}$ are considered positive.

Blood samples for GLP-1 measurement were taken in EDTA tubes and put on ice immediately, centrifuged for plasma content and stored at $-80^{\circ} \mathrm{C}$. GLP-1 concentrations in plasma were measured by radioimmunoassays after extraction of plasma with $70 \%$ ethanol (vol/vol, final concentration). Carboxyterminal GLP-1 immunoreactivity was determined using antiserum 89390 which has an absolute requirement for the intact amidated carboxyterminus of GLP-1 7-36amide and cross reacts $<0.01 \%$ with carboxyterminally truncated fragments and 89\% with GLP-1 9-36amide, the primary metabolite of dipeptidyl peptidase IV-mediated degradation. The sum of the two components (total GLP-1 concentration) reflects the rate of secretion of the $\mathrm{L}$ cell. Sensitivity was below $1 \mathrm{pmol} / \mathrm{L}$ and intra-assay $\mathrm{CV}$ was $<5 \%$.

\section{Insulin sensitivity and BC}

From the OGTT, fasting and peripheral (dynamic) insulin sensitivities were determined by the Quantitative Insulin Sensitivity Check Index (QUICKI) and the Oral Glucose Insulin Sensitivity Index (OGIS), respectively. These indices have been validated against clamp in T2DM. ${ }^{15}$ From the IVGTT, insulin sensitivity was estimated with calculated SI (CSI), a validated surrogate index of insulin sensitivity index from the minimal model (SI). ${ }^{16}$

Homeostatic model assessment for BC (HOMA-\%B) was used as a measure of fasting $\beta$-cell activity ${ }^{15}{ }^{17}$ Insulin secretion was evaluated with the area under the curve (AUC), calculated using the trapezoidal method. During the OGTT, insulin secretion was evaluated with the AUC of $\mathrm{C}$ peptide $\left(\mathrm{AUC}_{\mathrm{c} \text { peptide }}\right.$ ) and the amount of insulin reaching the periphery (posthepatic) with AUC of insulin $\left(\mathrm{AUC}_{\text {insulin }}\right)$. Early phase insulin response during OGTT was calculated for the first $30 \mathrm{~min}$ using insulinogenic index, $\quad \mathrm{IGI}=\Delta \mathrm{I}_{30} / \Delta \mathrm{G}_{30}=\left(\mathrm{I}_{30}-\mathrm{I}_{\text {basal }}\right) /$ $\left(\mathrm{G}_{30}-\mathrm{G}_{\text {basal }}\right)$, while the corresponding index for C peptide, $\mathrm{IGI}_{\mathrm{C} \text { peptide was }} \Delta \mathrm{CP}_{30} / \Delta \mathrm{G}_{30}=\left(\mathrm{CP}_{30}-\mathrm{CP}_{\text {basal }}\right) /$ $\left(\mathrm{G}_{30}-\mathrm{G}_{\text {basal }}\right)$. Acute insulin response (AIR) during IVGTT was calculated from the suprabasal average of insulin in the 3-10 min interval after the glucose bolus. The BC describes the ability of glucose to stimulate insulin release from $\beta$-cells. It was calculated as incremental $\mathrm{AUC}_{\text {insulin }}\left(\Delta \mathrm{AUC}_{\mathrm{insulin}}\right)$ and $\mathrm{AUC}_{\mathrm{c}}$ peptide $\left(\Delta \mathrm{AUC}_{\mathrm{c}}\right.$ peptide $)$ over the incremental $\mathrm{AUC}_{\text {glucose }}\left(\Delta \mathrm{AUC} \mathrm{C}_{\text {glucose }}\right)$ in both tests, which are $\mathrm{BC}_{\mathrm{OG}}$ during $\mathrm{OGTT}$ and $\mathrm{BC}_{\mathrm{IV}}$ during IVGTT. ${ }^{18}$ We also calculated the shape index (Whole-Ogtt-Shape-index, WHOSH) for glucose, insulin and $\mathrm{C}$ peptide, which correlate with a model-based parameter of BC. Shape indices quantify the degree of variation of a curve. Previous study has shown that a complex shape (ie, higher variability) is associated with better glucose tolerance condition. The $\mathrm{C}$ peptide shape index $\left(\mathrm{WHOSH}_{\mathrm{C} \text { peptide }}\right.$ ) has also been shown to correlate with a model-based parameter of BC. ${ }^{19}$

BC cannot be correctly assessed unless adjusted for the prevailing insulin resistance. ${ }^{20}$ Under normal conditions, a balance between insulin secretion and insulin sensitivity maintains the tight glucose regulation. The disposition index (DI) reflects the ability to maintain glucose regulation through a balance between insulin secretion and insulin sensitivity. DI was calculated using the product of insulin sensitivity and insulin secretion from OGTT using product of $\mathrm{OGIS} \times \Delta \mathrm{AUC}_{\text {insulin }}$ and from IVGTT using product of CSI $\times$ AIR.

\section{Assessment of incretin hormone secretion and incretin effect}

The incretin hormone, GLP-1, was measured during the 2-hour OGTT at times $0,15,30,60$ and $90 \mathrm{~min}$. The GLP-1 secretion was presented as total AUC (tAUC) calculated using the trapezoidal method. The relative response was calculated as fold increase of GLP-1 relative to baseline. Relative early response of GLP-1 (GLP $\mathrm{rAUC}_{0-15}$ ) was calculated as $\mathrm{tAUC}_{0-15} /$ (fasting concentration $\times 15 \mathrm{~min}$ ) and the relative full response $\left(\mathrm{GLP} \mathrm{rAUC}_{0-90}\right)$ was calculated as $\mathrm{tAUC}_{0-90} /$ (fasting concentration $\times 90 \mathrm{~min})$. The incretin effect was estimated by relating the differences in $\beta$-cell responses from $\mathrm{C}$ peptide between stimulation with oral and intravenous glucose. The incretin effect was estimated by the formula $100 \times\left(\mathrm{BC}_{\mathrm{OG}}-\mathrm{BC}_{\mathrm{IV}}\right) / \mathrm{BC}_{\mathrm{OG}} \cdot{ }^{21}$

\section{Statistical analyses}

With a ratio of YT2DM to control subjects of 2:1, a sample size of $28 \mathrm{~T} 2 \mathrm{DM}$ and 14 control subjects would have the $80 \%$ power to detect a mean difference of $70 \mathrm{~mL} / \mathrm{min} / \mathrm{m}^{2}$ in OGIS (eg, difference between T2DM mean of $350 \mathrm{ml} / \mathrm{min} / \mathrm{m}^{2}$ and control's mean of $420 \mathrm{~mL} / \mathrm{min} / \mathrm{m}^{2}$ ), with the common SD of 75 , and $\mathrm{p}<0.05 .{ }^{22}$ Besides, based on a previous study by Pacini et $a l,{ }^{21}$ assuming $66 \pm 25 \%$ is the incretin effect in 35 controls, 31 T2DM subjects were sufficient to detect a mean 
difference of $48 \pm 25 \%$ incretin effect, with $80 \%$ power and $\mathrm{p}<0.05$.

The data were collected and analyzed using Statistical Package for the Social Sciences (SPSS) V.20.0. The data were de-identified before their use in analyses. Data of categorical variables were presented in $\mathrm{n}(\%)$. Data of continuous variables were described in mean \pm SEM. Inferential analyses using $\chi^{2}$ test were performed between T2DM and control subject groups for demographics, clinical history, metabolic control, and development of comorbidities and complications. Fisher's exact tests were employed wherever assumptions for $\chi^{2}$ tests were not fulfilled. Independent Student's t-tests were employed to investigate the mean differences between T2DM and control groups for age, glycemic and metabolic parameters, indices for insulin sensitivity, BC and incretin effect. The relationship between glycemic control (HbA1c) and incretin effect was examined by Pearson's correlation.

\section{RESULTS}

\section{Study subjects}

Thirty subjects with clinical diagnosis of T2DM and 18 controls matched for gender, ethnicity and BMI were recruited for this study. Five youth with diabetes and three controls were excluded due to positive pancreatic autoantibodies. Subsequent comparisons were made between the 25 youth with antibodies negative T2DM (YT2DM) and 15 matched controls. The YT2DM were on variable treatment regimens that include diet therapy alone $(n=2)$, metformin alone $(n=11)$, dual OADs $(n=4)$ and combination of $\mathrm{OAD}(\mathrm{s})$ and insulin $(n=8)$. The $\mathrm{HbAlc}$ was $10.0 \pm 4.0 \% \quad(86 \pm 43 \mathrm{mmol} / \mathrm{mol})$ with diet therapy alone, $7.7 \pm 1.6 \%(61 \pm 18 \mathrm{mmol} / \mathrm{mol})$ with metformin alone, $9.0 \pm 0.5 \% \quad(75 \pm 6 \mathrm{mmol} / \mathrm{mol})$ with dual OADs and $8.5 \pm 2.0 \%(69 \pm 21 \mathrm{mmol} / \mathrm{mol})$ with $\mathrm{OAD}(\mathrm{s})$ and insulin $(\mathrm{p}=0.336)$.

Table 1 summarizes subjects' characteristics and fasting metabolic profile. There were no significant differences in gender, ethnic distributions and pubertal staging but the YT2DM group was about 4 years younger than the controls. The YT2DM group was twice as likely to have either/or both parents with T2DM. Acanthosis nigricans, a marker of insulin resistance, was three times more likely in the YT2DM group. The YT2DM had greater visceral adiposity, despite similar total and subcutaneous adiposity compared with controls.

\section{Glucose, insulin and $C$ peptide responses during OGTT}

Figure 1A-C illustrates the glucose, insulin and $\mathrm{C}$ peptide excursion during OGTT. Glucose was higher at every time point in the YT2DM than controls. Fasting insulin and $\mathrm{C}$ peptide were higher in the YT2DM at baseline. The total pancreatic insulin secretion over 2 hours during the OGTT, as measured by AUC $_{\mathrm{C}}$ peptide were lower in the YT2DM compared with controls, 1630 \pm 207.3 vs $2796 \pm 217.8\left(\times 10^{2}\right) \quad \min \times \mathrm{pmol} / \mathrm{L} \quad(\mathrm{p}=0.001)$. The total insulin reaching the peripheral circulation, as measured by $\mathrm{AUC}_{\text {insulin }}$ were similarly lower in the

Table 1 Physical characteristics and fasting metabolic profile

\begin{tabular}{|c|c|c|c|}
\hline & YT2DM (n=25) & Control $(n=15)$ & p Value \\
\hline Age, range (years) & $18.5 \pm 0.92,(11-25)$ & $22.0 \pm 0.85,(13-24)$ & 0.008 \\
\hline Male:female & $12: 13$ & $7: 8$ & 0.935 \\
\hline Ethnicity-Malay:Chinese:others & $16: 6: 3$ & $12: 2: 1$ & $-^{\star}$ \\
\hline $\mathrm{BMI}\left(\mathrm{kg} / \mathrm{m}^{2}\right)$ & $30.2 \pm 1.05$ & $27.3 \pm 1.08$ & 0.081 \\
\hline Age at diagnosis of diabetes (years) & $16.1 \pm 0.92$ & - & - \\
\hline Duration of diabetes (months) & $23.1 \pm 6.42$ & - & - \\
\hline $\begin{array}{l}\text { Family history of diabetes (including first-degree } \\
\text { and second-degree relatives) }\end{array}$ & $24(96.0)$ & $12(80.0)$ & $0.139 \dagger$ \\
\hline \multicolumn{4}{|l|}{ Tanner stages } \\
\hline II-III & $3(12.0)$ & 0 & $0.279 \dagger$ \\
\hline IV-V & $22(88.0)$ & $15(100.0)$ & \\
\hline Acanthosis nigricans & $18(72.0)$ & $3(20.0)$ & 0.001 \\
\hline Fasting blood glucose (mmol/L) & $9.9 \pm 0.85$ & $4.5 \pm 0.06$ & $<0.001$ \\
\hline $\mathrm{HbA} 1 \mathrm{c}(\%)$ & $8.4 \pm 0.37$ & $5.3 \pm 0.09$ & $<0.001$ \\
\hline $\mathrm{HbA1c}(\mathrm{mmol} / \mathrm{mol})$ & $68 \pm 4$ & $34 \pm 1$ & $<0.001$ \\
\hline Microalbuminuria & $14(56.0)$ & 0 & $<0.001$ \\
\hline Systolic BP (mm Hg) & $120.8 \pm 2.31$ & $116.1 \pm 2.72$ & 0.200 \\
\hline Diastolic BP (mm Hg) & $73.8 \pm 2.00$ & $69.5 \pm 2.22$ & 0.173 \\
\hline Waist:hip ratio & $0.9 \pm 0.01$ & $0.8 \pm 0.02$ & 0.011 \\
\hline Total adipose tissue $\left(\mathrm{cm}^{2}\right)$ & $421 \pm 31.0$ & $364 \pm 47.0$ & 0.297 \\
\hline Visceral adipose tissue $\left(\mathrm{cm}^{2}\right)$ & $79 \pm 7.6$ & $53 \pm 8.5$ & 0.035 \\
\hline Subcutaneous adipose tissue $\left(\mathrm{cm}^{2}\right)$ & $339 \pm 25.9$ & $302 \pm 41.0$ & 0.433 \\
\hline
\end{tabular}



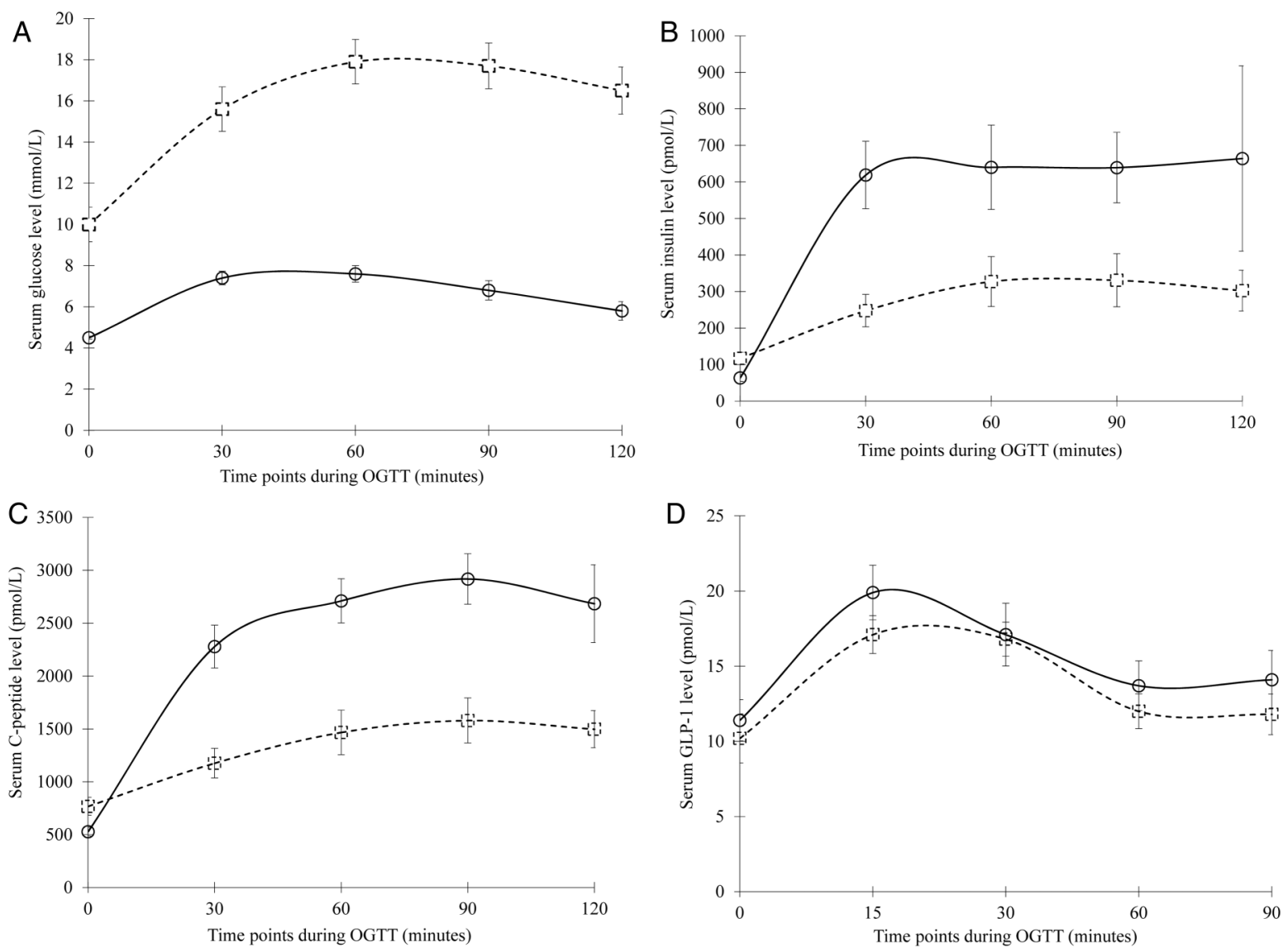

Figure 1 Plasma glucose (A), serum insulin (B), serum C peptide (C) and plasma GLP-1 level (D) during the 2-hour OGTT among subjects with normal glucose tolerance (NGT) (circles with solid line) and YT2DM (squares with dotted line). Data were presented in mean \pm SEM. GLP-1, glucagon-like peptide-1; OGTT, oral glucose tolerance test; YT2DM, youth onset type 2 diabetes mellitus.

YT2DM, $3453 \pm 647.3$ vs $6240 \pm 748.4\left(\times 10^{1}\right) \mathrm{min} \times \mathrm{pmol} / \mathrm{L}$ $(\mathrm{p}=0.009)$.

\section{Insulin sensitivity and BC}

The indices generated from OGTT and IVGTT are reported in table 2 and figure $2 \mathrm{~A}-\mathrm{C}$. The YT2DM had lower fasting insulin sensitivity (QUICKI) and peripheral insulin sensitivity (OGIS) than the controls. The IVGTT-derived CSI was also lower in the YT2DM group. The early phase insulin responses to glucose challenge, as measured by AIR, were diminished by more than $80 \%$ when compared with the controls. IGI and IGI $_{\mathrm{C}}$ peptide were similarly lower though they did not reach statistical significance. The $\mathrm{BC}, \mathrm{BC}_{\mathrm{OG}-\text { insulin }}$ and $\mathrm{BC}_{\mathrm{IV} \text {-insulin }}$ were reduced in the YT2DM group by $86 \%$ and $62 \%$, respectively. The reduced $\mathrm{BC}$ was further confirmed by the lower $\mathrm{WHOSH}_{\mathrm{C}}$ peptide in the YT2DM. The DI, both derived from OGTT and IVGTT, was also reduced in the YT2DM subjects.

\section{Incretin hormone secretion and incretin effect}

The GLP-1 responses during OGTT are shown in figure 1D. There was no difference in GLP-1 secretion at baseline and all subsequent time points between YT2DM and control subjects. The total GLP-s secretion $\left(\right.$ tAUC $\left._{0-90}\right)$ for YT2DM and control groups were $1223.4 \pm 79.40$ and $1347.5 \pm 125.84 \mathrm{pmol} / \mathrm{L}$, respectively $(\mathrm{p}=0.385)$. Early phase and total GLP-1 secretion were otherwise similar between groups both in absolute (tAUC) and relative (rAUC) terms. Despite the similar level of GLP-1 secretion, incretin effect was significantly reduced in the YT2DM group $(12.1 \pm 8.93 \%$ vs 70.0 $\pm 4.03 \%, \mathrm{p}<0.001$; figure 2D). The incretin effect was inversely correlated with HbAlc in our study $\left(r^{2}=0.271\right.$, $\mathrm{p}<0.001)$.

\section{DISCUSSION}

T2DM in the youth from a multiethnic Malaysian population, when compared with peers with normal glucose tolerance, is characterized by decreased insulin sensitivity and relative impairment in BC. In the fasting state, insulin sensitivity (QUICKI) and BC (HOMA-\%B) were markedly lower in YT2DM, reflecting hepatic insulin resistance $^{23}$ and impaired $\beta$-cell activity, respectively. Majority of our participants (88\% of YT2DM and $100 \%$ controls) had Tanner stage IV and V. The effect of puberty on the difference observed in insulin sensitivity is therefore minimal. Decreased insulin sensitivity and BC are also observed in studies among Korean, Taiwanese and Indian youth with T2DM. ${ }^{24-26}$ 
Table 2 OGTT-modeled and IVGTT-modeled parameters of insulin sensitivity and $\beta$-cell function

\begin{tabular}{|c|c|c|c|}
\hline & YT2DM (n=25) & Control $(n=15)$ & p Value \\
\hline \multicolumn{4}{|l|}{ OGTT-modeled parameters } \\
\hline \multicolumn{4}{|l|}{ Insulin sensitivity } \\
\hline QUICKI & $0.21 \pm 0.006$ & $0.27 \pm 0.010$ & $<0.001$ \\
\hline OGIS $\left(\mathrm{mL} / \mathrm{min} / \mathrm{m}^{2}\right)$ & $281.8 \pm 16.54$ & $421.3 \pm 16.46$ & $<0.001$ \\
\hline \multicolumn{4}{|l|}{$\beta$-cell function } \\
\hline HOMA-\%B & $110.9 \pm 26.88$ & $230.9 \pm 42.10$ & 0.016 \\
\hline IGI (pmol/mmol) & $32.5 \pm 13.39$ & $378.4 \pm 181.53$ & 0.080 \\
\hline $\mathrm{IGI}_{\mathrm{C} \text { peptide }}(\mathrm{pmol} / \mathrm{mmol})$ & $97.4 \pm 27.85$ & $1584.2 \pm 985.26$ & 0.155 \\
\hline $\left.\mathrm{BC}_{\mathrm{OG}-\text { insulin }}(\mathrm{pmol} / \mathrm{mmol})\right]$ & $34.1 \pm 11.25$ & $244.3 \pm 41.57$ & $<0.001$ \\
\hline BC $\mathrm{OG}-\mathrm{C}$ peptide $(\mathrm{pmol} / \mathrm{mmol})]$ & $2978 \pm 772.0$ & $15267 \pm 2542.2$ & $<0.001$ \\
\hline \multicolumn{4}{|l|}{ Shape indices } \\
\hline WHOSH $\mathrm{glucose}\left(\times 10^{-3}\right)\left(\mathrm{min}^{-2} \times \mathrm{mmol} / \mathrm{L}\right)$ & $3.2 \pm 0.50$ & $2.0 \pm 0.20$ & 0.079 \\
\hline $\mathrm{WHOSH}_{\text {insulin }}\left(\times 10^{-2}\right)\left(\mathrm{min}^{-2} \times \mu \mathrm{U} / \mathrm{mL}\right)$ & $2.8 \pm 0.60$ & $7.0 \pm 1.33$ & 0.008 \\
\hline $\mathrm{WHOSH}_{\mathrm{C} \text { peptide }}\left(\times 10^{-3}\right)\left(\mathrm{min}^{-2} \times \mathrm{ng} / \mathrm{mL}^{*}\right)$ & $1.3 \pm 0.28$ & $3.4 \pm 0.60$ & 0.004 \\
\hline \multicolumn{4}{|l|}{ DI } \\
\hline DI $\left.\left(\mathrm{mL} / \mathrm{min} / \mathrm{m}^{2}\right) \times(\min \times \mathrm{pmol} / \mathrm{L})\right]\left(\times 10^{8}\right)$ & $600.6 \pm 164.33$ & $2239.6 \pm 228.58$ & $<0.001$ \\
\hline \multicolumn{4}{|l|}{ IVGTT-modeled parameters } \\
\hline \multicolumn{4}{|l|}{ Insulin sensitivity } \\
\hline $\mathrm{CSI}\left(\times 10^{-4}\right)\left(\left(\mathrm{min}^{-1}\right) \times(\mu \mathrm{U} / \mathrm{mL})^{-1}\right]$ & $1.7 \pm 0.24$ & $4.0 \pm 0.81$ & 0.015 \\
\hline \multicolumn{4}{|l|}{$\beta$-cell function } \\
\hline AIR (pmol/L) & $73.5 \pm 25.49$ & $487.5 \pm 64.49$ & $<0.001$ \\
\hline $\left.\mathrm{BC}_{\mathrm{IV} \text {-insulin }}(\mathrm{pmol} / \mathrm{mmol})\right]$ & $19.8 \pm 5.93$ & $51.5 \pm 8.06$ & 0.003 \\
\hline $\left.\mathrm{BC}_{\mathrm{IV}-\mathrm{C} \text { peptide }}(\mathrm{pmol} / \mathrm{mmol})\right]$ & $2297.3 \pm 422.48$ & $3556.2 \pm 495.28$ & 0.065 \\
\hline \multicolumn{4}{|l|}{ DI } \\
\hline DI $\left[\left(\mathrm{mL} / \mathrm{min} / \mathrm{m}^{2}\right) \times(\min \times \mathrm{pmol} / \mathrm{L})\right]\left(\times 10^{4}\right)$ & $60.8 \pm 13.18$ & $1939.7 \pm 617.60$ & 0.009 \\
\hline
\end{tabular}

Obesity is considered one of the major triggers for YT2DM, with inadequate insulin secretion to compensate for the rising insulin resistance driven by obesity and puberty. ${ }^{3}$ The Asian YT2DM in our study have lower mean BMI than the African-American and Caucasian adolescents with $\mathrm{T} 2 \mathrm{DM}$ reported in previous studies $^{8} \quad 92728$ but similar insulin sensitivity (OGIS). ${ }^{8}$ About $50 \%$ of the Taiwanese youth with T2DM had $\mathrm{BMI}<27 \mathrm{~kg} / \mathrm{m}^{2}$ and insulin sensitivity were similar in the obese and non-obese YT2DM. ${ }^{25}$

In our study, the reduction in $\mathrm{BC}$ derived during OGTT $\left(\mathrm{BC}_{\mathrm{OG}}\right)$ in YT2DM was more pronounced than the reduction in insulin sensitivity (OGIS), suggesting that $\beta$-cell dysfunction plays a more important role in reducing glucose tolerance. There was also impaired ability of the $\beta$-cell to adjust for the prevailing insulin resistance, as evidenced by reduced DI. These observations were consistent with previous studies which demonstrated greater impairment in $\mathrm{BC}$ relative to insulin sensitivity in youth with T2DM. ${ }^{25} 2629$

Our result adds to the scarce literature in youth with T2DM by providing novel information on the incretin effect and GLP-1 concentrations during the OGTT. We demonstrated that YT2DM have similar GLP-1 concentration in response to the oral glucose compared with control subjects with normal glucose tolerance. This is consistent with findings from two meta-analyses in adults with $\mathrm{T}_{2} \mathrm{DM}^{30} 31$ despite earlier contrasting reports in smaller studies. $^{32} 33$ The ADDITION-PRO study, based on a population of screen-detected diabetes also demonstrated reduced GLP-1, especially late GLP-1 responses at 120 min, during an OGTT in screen-detected T2DM. ${ }^{34}$ We did not capture GLP-1 level at $120 \mathrm{~min}$. However, studies showed that GLP-1 level generally peak at $30 \mathrm{~min}$ and reach a plateau by $90 \mathrm{~min}$ after oral glucose challenge. ${ }^{102435}$ It may be safe to assume that GLP-1 level at $90 \mathrm{~min}$ is similar to that at $120 \mathrm{~min}$. The discrepancy may reflect the different population studied since GLP-1 secretion has been shown to be affected by diabetes duration, severity of diabetes, age, sex and BMI. ${ }^{34}$ Our YT2DM were younger, with short duration of diabetes but significant degree of hyperglycemia. The majority of our YT2DM were on metformin which has been demonstrated to increase GLP-1 secretion. ${ }^{36}$ The 'good' level of GLP-1 secretion may also be due to the residual effect of metformin even though our subjects had their medications stopped for a minimum of 5 days prior to the OGTT. Korean children and adolescents with T2DM who were treatment naive were also found to have preserved intact GLP-1 secretion when assessed during OGTT. ${ }^{24}$

Despite the similar GLP-1 secretion, the incretin effect was reduced by more than $80 \%$ in our YT2DM compared with controls. Lesser degree of reduction in incretin effect has also been observed in two other studies 
Figure 2 OGIS (A), BC (B), DI (C) derived from OGTT parameters, and incretin effect (D) among subjects with YT2DM (bar graph with dots) and NGT (bar graph without filling pattern). Data were presented in mean \pm SEM. BC, $\beta$-cell function; DI, disposition index; OGIS, Oral Glucose Insulin Sensitivity Index; OGTT, oral glucose tolerance test; YT2DM, youth onset type 2 diabetes mellitus.
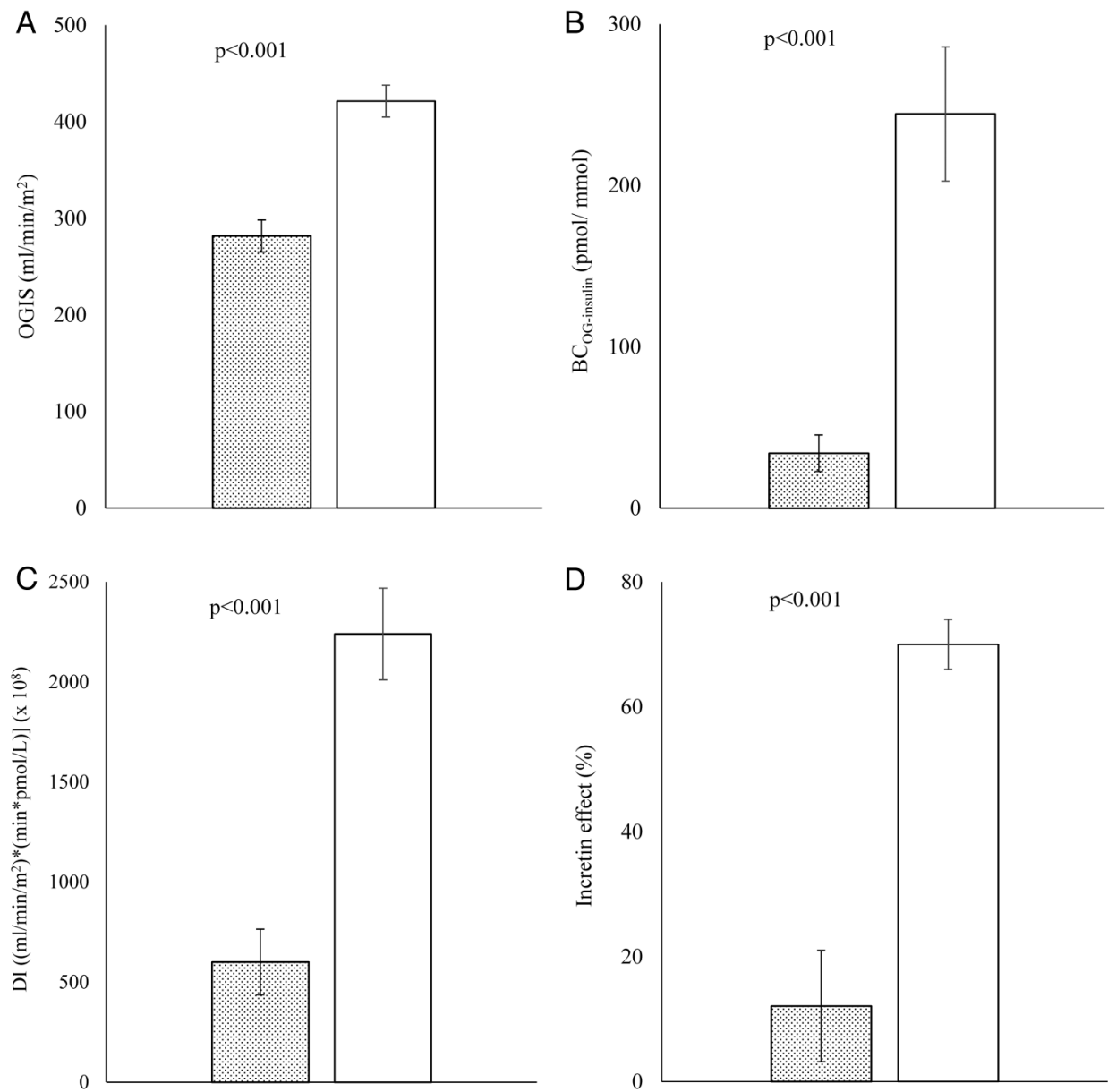

among non-Asian youth with T2DM. ${ }^{10} 37$ However, the incretin effect was derived differently from all three studies making direct comparison inaccurate. The greater reduction in incretin effect in our study may be due to the poorer glycemic control among our subjects since hyperglycemia has been proposed to downregulate GLP-1 receptor expression on $\beta$-cells and cause 'GLP-1 resistance'. ${ }^{34}$ We also found a significant inverse correlation between HbAlc and incretin effect. The lack of compensatory mechanisms, as shown by the DI may be partly ascribed to the impaired incretin effect, observed without reduction in GLP-1. Further clinical studies in YT2DM are needed to establish if incretin-based therapy can benefit glycemic control in YT2DM. The possibility of 'GLP-1 resistance' could also have important implications for the design of new therapies based on modulations of the GLP-1 pathways.

\section{CONCLUSIONS}

The current study adds to the scarce literature in adolescents with T2DM of Asian descent. In this multiethnic Asian cohort, pathophysiology of YT2DM is characterized by marked impaired $\mathrm{BC}$ in the presence of insulin resistance. Incretin effect is impaired in adolescents with T2DM compared with controls, possibly without reduction in GLP-1, similar to that seen in adult T2DM. This understanding can help guide the choice of therapeutic modalities and is relevant to all physicians in our increasingly globalized world.

\section{Author affiliations}

${ }^{1}$ Penang Medical College, Penang, Malaysia

${ }^{2}$ Department of Medicine, Penang General Hospital, Penang, Malaysia

${ }^{3}$ Metabolic Unit, Institute of Neuroscience, National Research Council, Padova, Italy

${ }^{4}$ Clinical Research Centre, Seberang Jaya Hospital, Penang, Malaysia

${ }^{5}$ Kepala Batas Hospital, Penang, Malaysia

${ }^{6}$ Department of Medicine, Sarawak General Hospital, Sarawak, Malaysia

${ }^{7}$ Department of Paediatrics, Hospital Putrajaya, Malaysia

${ }^{8}$ NNF Centre for Basic Metabolic Research, University of Copenhagen, Copenhagen, Denmark

${ }^{9}$ Department of Cardiovascular, Diabetes and Nutrition Research Centre, Institute for Medical Research, Kuala Lumpur, Malaysia

Acknowledgements The authors thank the nurses of the clinical research center for expert nursing assistance, and Infokinetics for research assistance and administrative support. Last but not least, the authors express their sincere thanks to the participating subjects and their family. This study has been presented for General Poster Session and Moderated Poster Discussion at the American Diabetes Association's 76th Scientific Sessions, June 10-14, 2016, in New Orleans, Louisiana. The abstract has been published in the Scientific Sessions Abstract Book, as the June 2016 supplement to the Journal Diabetes. Part of this study has also been presented at the Young Investigator Award at the Diabetes Asia Conference, October 6-9, 2016 in Kuala Lumpur, Malaysia.

Contributors TPY conceptualized and designed the study, obtained funding and drafted the initial manuscript. GP and AT performed the modeling 
analyses of the OGTT, IVGTT and the incretin effect, helped in the interpretation of the results and critically reviewed and edited the manuscript. $\mathrm{CPH}$ maintained the database, performed statistical analyses, and critically reviewed and edited the manuscript. SLL, FHST, CVT, JYHH, FMZ collected data in each center and reviewed the manuscript. JJH and WNWM performed the laboratory measurements and reviewed and edited the manuscript. All authors approved the final version for submission. TPY is the guarantor of this work and, as such, had full access to all the data in the study and takes responsibility for the integrity of the data and the accuracy of the data analysis.

Funding This work was supported by research funding from the Ministry of Health Malaysia (NMRR-12-1042-13254), the Malaysian Endocrine and Metabolic Society (MEMS) and Novartis Malaysia Sdn Bhd.

Competing interests None declared.

Ethics approval Malaysian Medical Research and Ethics Committee.

Provenance and peer review Not commissioned; externally peer reviewed.

Data sharing statement All data are included in this manuscript. Raw data are hosted at Penang Medical College, and available for sharing on request.

Open Access This is an Open Access article distributed in accordance with the Creative Commons Attribution Non Commercial (CC BY-NC 4.0) license, which permits others to distribute, remix, adapt, build upon this work noncommercially, and license their derivative works on different terms, provided the original work is properly cited and the use is non-commercial. See: http:// creativecommons.org/licenses/by-nc/4.0/

\section{REFERENCES}

1. D'Adamo E, Caprio S. Type 2 diabetes in youth: epidemiology and pathophysiology. Diabetes Care 2011;34(Suppl 2):S161-S65.

2. Constantino MI, Molyneaux L, Limacher-Gisler F, et al. Long-term complications and mortality in young-onset diabetes: type 2 diabetes is more hazardous and lethal than type 1 diabetes. Diabetes Care 2013:36:3863-9.

3. Type 2 diabetes in children and adolescents. American Diabetes Association. Diabetes Care 2000;23:381-9.

4. Dabelea D, Bell RA, D'Agostino RB Jr, et al. Incidence of diabetes in youth in the United States. JAMA 2007;297:2716-24.

5. Ehtisham S, Hattersley AT, Dunger DB, et al. First UK survey of paediatric type 2 diabetes and MODY. Arch Dis Child 2004;89:526-9.

6. Bacha F, Gungor N, Lee S, et al. Progressive deterioration of $\beta$-cell function in obese youth with type 2 diabetes. Pediatr Diabetes 2013:14:106-11.

7. Cali AM, Man CD, Cobelli C, et al. Primary defects in beta-cell function further exacerbated by worsening of insulin resistance mark the development of impaired glucose tolerance in obese adolescents. Diabetes Care 2009;32:456-61.

8. Tfayli $\mathrm{H}$, Arslanian S. Pathophysiology of type 2 diabetes mellitus in youth: the evolving chameleon. Arq Bras Endocrinol Metabol 2009:53:165-74.

9. McQuaid S, O'Gorman DJ, Yousif O, et al. Early-onset insulinresistant diabetes in obese Caucasians has features of typical type 2 diabetes, but 3 decades earlier. Diabetes Care 2005:28:1216-18.

10. Michaliszyn SF, Mari A, Lee S, et al. $\beta$-cell function, incretin effect, and incretin hormones in obese youth along the span of glucose tolerance from normal to prediabetes to type 2 diabetes. Diabetes 2014;63:3846-55.

11. Kobayashi K, Amemiya S, Higashida K, et al. Pathogenic factors of glucose intolerance in obese Japanese adolescents with type 2 diabetes. Metab Clin Exp 2000;49:186-91.

12. World Health Organisation. Definition and diagnosis of diabetes mellitus and intermediate hyperglycaemic: a report of a WHO/IDF consultation. Geneva, Switzerland, 2006.

13. Pacini $\mathrm{G}$, Tonolo $\mathrm{G}$, Sambataro $\mathrm{M}$, et al. Insulin sensitivity and glucose effectiveness: minimal model analysis of regular and insulin-modified FSIGT. Am J Physiol 1998;274(Pt 1):E592-9.

14. Orskov $\mathrm{C}$, Rabenhoj $\mathrm{L}$, Wettergren $\mathrm{A}$, et al. Tissue and plasma concentrations of amidated and glycine-extended glucagon-like peptide I in humans. Diabetes 1994;43:535-9.
15. Pacini G, Mari A. Methods for clinical assessment of insulin sensitivity and $\beta$-cell function. Best Pract Res Clin Endocrinol Metab 2003;17:305-22.

16. Tura A, Sbrignadello $S$, Succurro E, et al. An empirical index of insulin sensitivity from short IVGTT: validation against the minimal model and glucose clamp indices in patients with different clinical characteristics. Diabetologia 2010;53:144-52.

17. Levy JC, Matthews DR, Hermans MP. Correct homeostasis model assessment (HOMA) evaluation uses the computer program. Diabetes Care 1998;21:2191-2.

18. Tura A, Kautzky-Willer A, Pacini G. Insulinogenic indices from insulin and C-peptide: comparison of beta-cell function from OGTT and IVGTT. Diabetes Res Clin Pract 2006:72:298-301.

19. Tura A, Morbiducci U, Sbrignadello S, et al. Shape of glucose, insulin, C-peptide curves during a 3-h oral glucose tolerance test: any relationship with the degree of glucose tolerance? Am J Physiol Regul Integr Comp Physiol 2011;300:R941-8.

20. Ahren B, Pacini G. Islet adaptation to insulin resistance: mechanisms and implications for intervention. Diabetes Obes Metab 2005;7:2-8.

21. Pacini G, Tura A, Winhofer $Y$, et al. Incretin effect in women with former gestational diabetes within a short period after delivery. Int J Endocrinol 2012;2012:247392.

22. Kanauchi M. A new index of insulin sensitivity obtained from the oral glucose tolerance test applicable to advanced type 2 diabetes. Diabetes Care 2002;25:1891-2.

23. Home PD, Pacini G. Hepatic dysfunction and insulin insensitivity in type 2 diabetes mellitus: a critical target for insulin-sensitizing agents. Diabetes Obes Metab 2008;10:699-718.

24. Park SH, Jung MH, Cho WK, et al. Incretin secretion in obese Korean children and adolescents with newly diagnosed type 2 diabetes. Clin Endocrinol (Oxf) 2016;84:72-9.

25. Pei D, Hsiao CF, Hung YJ, et al. The insulin sensitivity, glucose sensitivity, and acute insulin response to glucose load in adolescent type 2 diabetes in Taiwanese. Diabetes Metab Res Rev 2006;22:26-33.

26. Mohan V, Amutha A, Ranjani $\mathrm{H}$, et al. Associations of beta-cell function and insulin resistance with youth-onset type 2 diabetes and prediabetes among Asian Indians. Diabetes Technol Ther 2013;15:315-22.

27. Knop FK, Vilsboll T, Hojberg PV, et al. Reduced incretin effect in type 2 diabetes: cause or consequence of the diabetic state? Diabetes 2007;56:1951-9.

28. Gungor N, Bacha F, Saad R, et al. Youth type 2 diabetes: insulin resistance, beta-cell failure, or both? Diabetes Care 2005;28:638-44.

29. Bacha F, Gungor N, Lee S, et al. In vivo insulin sensitivity and secretion in obese youth: what are the differences between normal glucose tolerance, impaired glucose tolerance, and type 2 diabetes? Diabetes Care 2009;32:100-5.

30. Nauck MA, Vardarli I, Deacon CF, et al. Secretion of glucagon-like peptide-1 (GLP-1) in type 2 diabetes: what is up, what is down? Diabetologia 2011:54:10-18.

31. Calanna S, Christensen M, Holst JJ, et al. Secretion of glucagonlike peptide-1 in patients with type 2 diabetes mellitus: systematic review and meta-analyses of clinical studies. Diabetologia 2013;56:965-72.

32. Toft-Nielsen MB, Damholt MB, Madsbad S, et al. Determinants of the impaired secretion of glucagon-like peptide-1 in type 2 diabetic patients. J Clin Endocrinol Metab 2001;86:3717-23.

33. Vilsboll T, Krarup T, Deacon CF, et al. Reduced postprandial concentrations of intact biologically active glucagon-like peptide 1 in type 2 diabetic patients. Diabetes 2001;50:609-13.

34. Faerch K, Torekov SS, Vistisen D, et al. GLP-1 response to oral glucose is reduced in prediabetes, screen-detected type 2 diabetes, and obesity and influenced by sex: the ADDITION-PRO Study. Diabetes 2015;64:2513-25.

35. Plamboeck A, Veedfald S, Deacon CF, et al. Characterisation of oral and i.v. glucose handling in truncally vagotomised subjects with pyloroplasty. Eur J Endocrinol 2013;169:187-201.

36. Mannucci E, Tesi F, Bardini G, et al. Effects of metformin on glucagon-like peptide-1 levels in obese patients with and without Type 2 diabetes. Diabetes Nutr Metab 2004;17:336-42.

37. Aulinger BA, Vahl TP, Prigeon RL, et al. The incretin effect in obese adolescents with and without type 2 diabetes: impaired or intact? Am J Physiol Endocrinol Metab 2016;310:E774-81. 